\title{
How one pandemic led to another: ASFV, the disruption contributing to SARS-CoV-2 emergence in Wuhan
}

\author{
Wei Xia ${ }^{1}$, Joseph Hughes ${ }^{2}$, David L. Robertson ${ }^{2}$, Xiaowei Jiang ${ }^{3^{*}}$ \\ ${ }^{1}$ National School of Agricultural Institution and Development, South China Agricultural \\ University, Guangzhou, China. \\ ${ }^{2} \mathrm{MRC}$-University of Glasgow Centre for Virus Research (CVR), Glasgow, UK. \\ ${ }^{3}$ Department of Biological Sciences, Xi'an Jiaotong-Liverpool University (XJTLU), Suzhou, \\ China.
}

*Correspondence: Xiaowei.Jiang@xjtlu.edu.cn

\begin{abstract}
The spillover of a virus from one host species to another requires both molecular and ecological risk factors to align. While extensive research both before and after the emergence of SARS-CoV-2 in 2019 implicates horseshoe bat as the significant reservoir genus for the new coronavirus, it remains unclear why it emerged at this time. One massive disruption to human-animal contact in 2019 is linked to the on-going African swine fever virus (ASFV) pandemic. This began in Georgia in 2007 and was introduced to China in 2018. Pork is the major meat source in the Chinese diet. Severe fluctuations in the pork market prior to December 2019, may have increased the transmission of zoonotic pathogens, including severe acute respiratory syndrome-related coronaviruses, from wildlife to humans, wildlife to livestock and non-local animals to local animals. The major production and consumption regions for pork are geographically separated in China. The dramatic shortage of pork following restrictions of pig movement and culling resulted in price increases, leading to alternative sources of meat and unusual animal and meat movements nationwide often involving wildlife and thus greatly increased opportunities for human-Sarbecovirus contacts. Pork prices were particularly high in southern provinces (Guangdong, Guangxi, Fujian, Jiangxi, Hunan, and Hubei), where wildlife is farmed on different scales and more frequently consumed. Shandong experienced the biggest losses in pork production ( 1.7 million metric tons), which is also the largest mink farming province. Hence, human exposure to SARS-CoV-2 from wildlife or infected animals are more likely to have taken place in 2019, when China was experiencing the worst effects of the ASFV pandemic.
\end{abstract}

\section{Introduction}

SARS-CoV-2, a sister lineage of SARS-CoV from the Sarbecovirus subgenus of Betacoronavirus, emerged in Wuhan city, China, in late 2019 with many cases associated with the Huanan Seafood Market. While it is ambiguous whether the Seafood market is the source of the spillover event (due to early cases not linked to the market) or was just a focal point of early infections, epidemiological data categorically confirm Hubei province as the probable epicentre of the SARS-CoV-2 pandemic. Although there are numerous studies exploring the natural origins of the new coronavirus ${ }^{1-7}$, it remains a mystery from where and how SARS-CoV-2 was introduced to Wuhan city. We propose that uncovering the origins of zoonotic pathogen emergence like SARS-CoV-2 should have a socioeconomic perspective, i.e., consider broader societal factors that contribute to virus emergence and any changes that might have increased the probability of spillover. 
There are usually several important barriers to be overcome for a successful zoonotic spillover event: opportunities for animal-human transmission, environmental and demographic barriers linked to ecological factors and host receptors and other molecular factors determined by host biology and immunity ${ }^{8,9}$. Assuming a human-adapted or generalist zoonotic pathogen already capable of breaking human-host barriers, ecological factors will play a key role in the chance of viral emergence. The interaction between the zoonotic pathogen and a susceptible human population with sufficient density for onward transmission, such as a mega city like Wuhan, is an important precondition for successful spillover and subsequent epidemic/pandemic. Human-induced changes can promote increased animal-human contact: human behavioral change, e.g., choosing alternative meat sources or travel to remote locations, and environmental change, which can be compounded as a result of socio-economic disruptions ${ }^{10}$.

Recently, the pork crisis has resulted in a change in animal meat consumption in China, which has significantly increased animal-human contact particularly of wildlife ${ }^{11}$. Additionally, human encroachment into once rural areas in China have increased significantly in recent years due to urbanisation and poverty reducing programs ${ }^{12}$. This has resulted in a significantly expanded transportation network linking places once remote to mega cities, increasing contact opportunities between reservoir hosts, such as bats and other potential intermediate animals, and humans ${ }^{10}$. The changes in meat availability in China is a consequence of another ongoing pandemic, driven by African swine fever virus (ASFV) infections in pigs and wild boars. It first reached Liaoning, Northeast of China on 3 August 2018, roughly one year before the current COVID-19 pandemic ${ }^{13,14}$, likely via infected wild boars or pork products. ASFV outbreaks in pigs have appeared several times in Europe since 1955 as a result of spread from Africa, where ASFV is endemic. ASFV was first described in East Africa where it has predominantly a sylvatic cycle (only infecting wildlife $)^{15}$. The current ASFV pandemic appears to have begun in Georgia, Europe in 2007 linked to travel to Africa (where ASFV is endemic) and since then has spread globally. China was the first country in Asia to report ASFV cases, but subsequently many more farmed and wild pigs in Asian countries have been infected. ASFV is a double stranded DNA virus of the genus Asfivirus in the Asfiviridae family and it causes, African swine fever (ASF), is a viral hemorrhagic disease with almost $100 \%$ lethality for which there is currently no vaccine or effective treatment. Culling is the only effective way to contain ASFV transmissions in pigs ${ }^{14}$.

Here we demonstrate that large-scale domestic pork shortages in China due to the nationwide ASFV epidemic, resulted in culling and provincial control measures abruptly breaking the regular meat supply chain and meat consumption structure, triggering massive and unusual animal and meat movements through food supply and cold chains. This disruption significantly increased the risks of human contact with the infected wildlife animals, their meat, contaminated meat and/or other susceptible animals. We hypothesis these frequent movements of alternative meat sources, their cold/supply chain workers and consumers, via well-connected high-speed road and railway networks, resulted in a successful spillover transmission of the SARS-CoV-2 progenitor in Wuhan possibly on more than one occasion. 


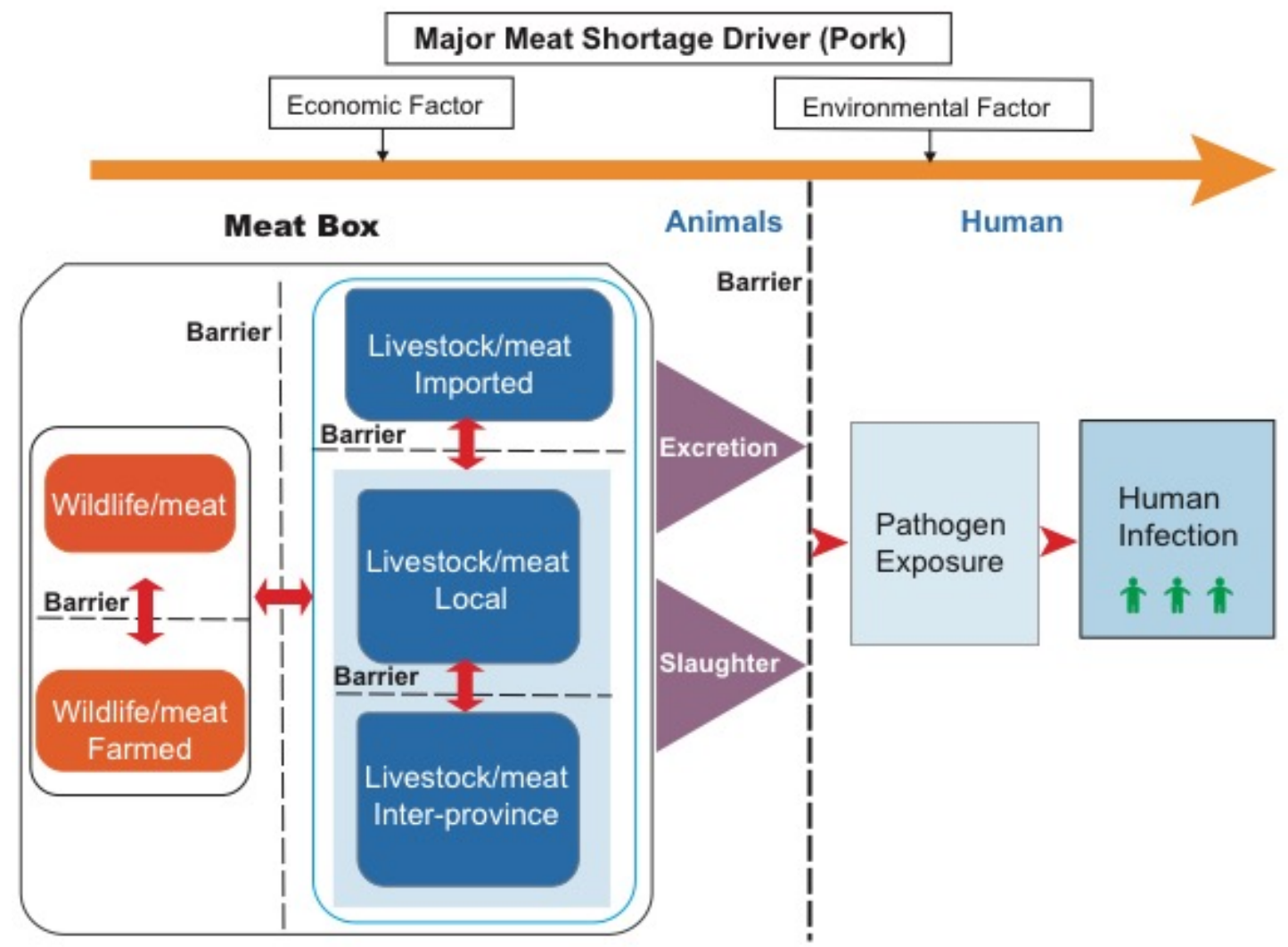

Figure 1. Major pork shortage increased the human contact probability with SARS-CoV-2 infected wildlife. This illustration shows that a major meat shortage with significant cultural and economic importance, such as pork in China, may reduce the barriers at many levels that usually stop spillovers and sustained animal-human zoonotic transmissions. These barriers usually restrict the zoonotic pathogens from reaching more susceptible populations. Alternative meat through supply/cold chains, such as wildlife animals, can frequently 'break' the barrier between animals and humans, increasing zoonotic spillover ${ }^{9}$.

\section{Results}

Pigs are economically and culturally important in China ${ }^{16,17}$ (Supplementary Notes and Supplementary Figures 1-6). Here, we propose four drivers that may explain how the ASFV's introduction to China may have contributed to SARS-CoV-2's emergence in Wuhan. The ASFV infections profoundly changed the structure of the Chinese meat market in the following ways: (1) a dramatic drop of pork supply, (2) a sharp rise and volatility in the price of pork, (3) new regulation on pig and pork transportation, and (4) increased use of wildlife. These drastic changes triggered the unusual movement of animals and their products, either live, chilled, frozen or processed, which increased the contact probability between humans and SARS-CoV-2 infected animal hosts or contaminated products. 


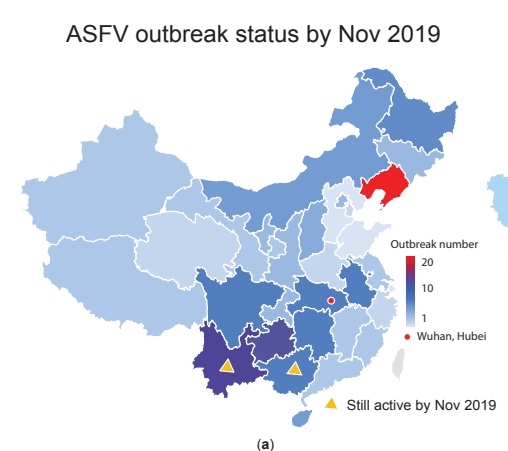

Pig price in Nov 2019

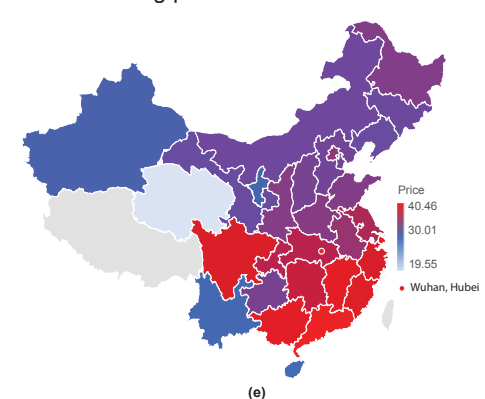

Total freeway length by 2019

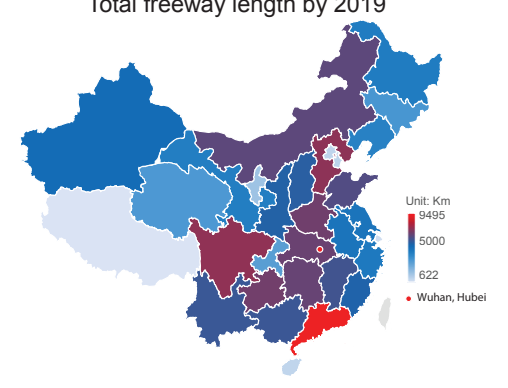

(g)
Pork production in 2019
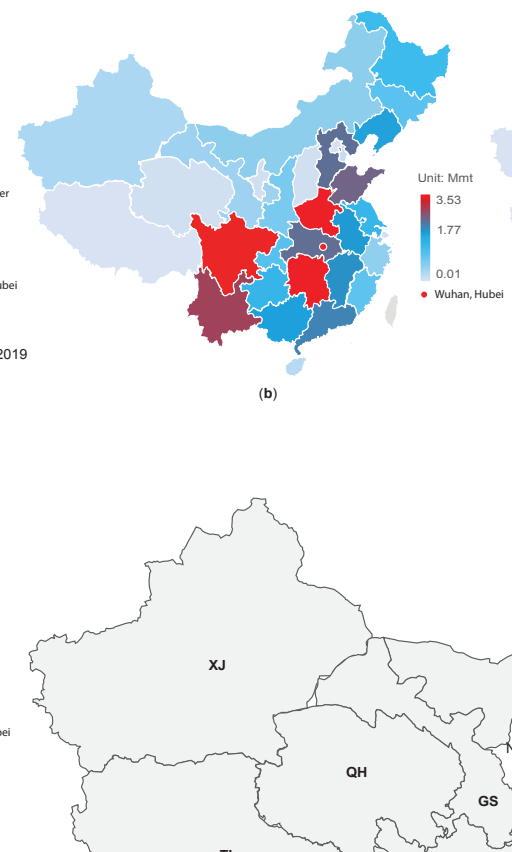

nCoV clade

nCoV clade

Recombinant

Wuhan (SARS-CoV-2)

- Guangzhou (SARS-CoV)

$+2$

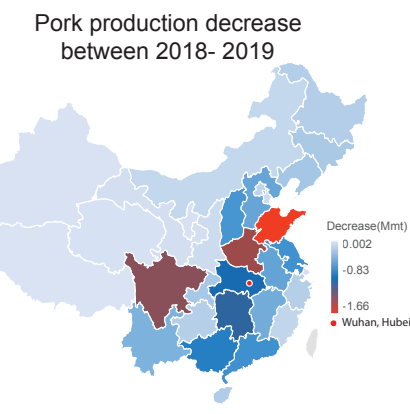

(c)

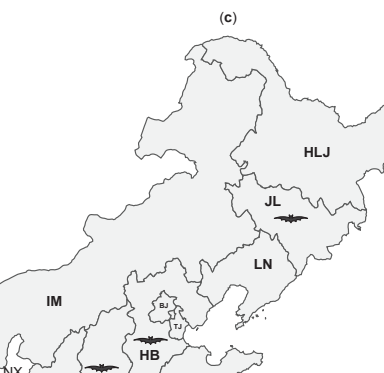

aH

Sc

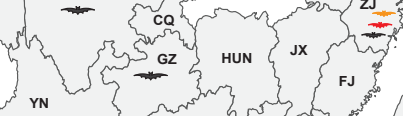

IN

HAN
Culled pigs between 2018-2019

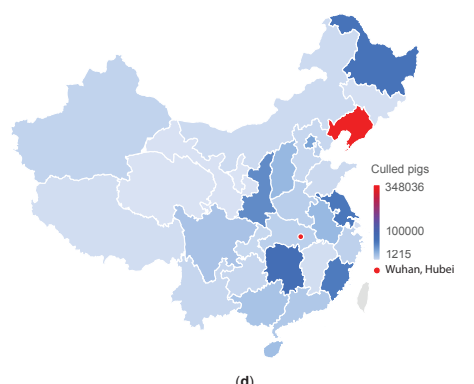

Daily pig price volatility in 2019

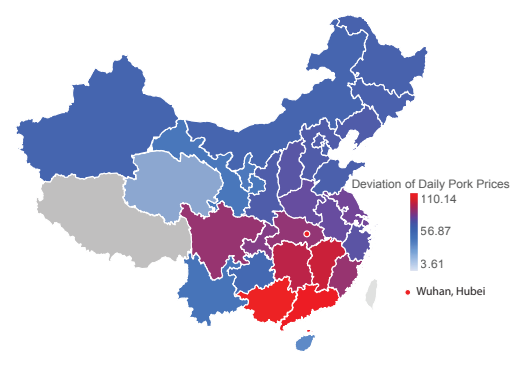

Increment in freeway length between 2018-2019

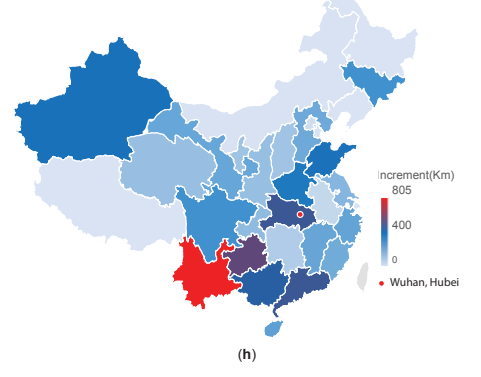


Figure 2. Linking ASFV outbreaks, pig production/reduction/culling/prices, freeway network length, and sampling locations of sarbecovirus genomes and their recombination among provinces in 2019 right before the SARS-CoV-2 emergence in Wuhan. Data for Hongkong, Macao, and Taiwan are not included. (a) The number of ASFV outbreaks and status as of November 2019 with Yunnan and Guangxi province still active; red and purple indicate more outbreaks. (b) Pork production in million metric tons (Mmt) in 2019; Hubei province located in the center with the three largest pig producers. (c) Decrease of pork production in million metric tons (Mmt) in 2019 compared to 2018. (d) The culled infected pigs between August 2018 and November 2019. (e) The average pig price in November 2019. (f) Price volatility in each province in 2019, an indicator for the stability of the pork market and prices, calculated by deviation of daily prices. (g) Total freeway length in each province in kilometers by the end of 2019. (h) Increment in freeway length in each province in kilometers in 2019. (i) Sampling locations of sarbecovirus genomes of SARS-CoV-2 related ('nCoV') or non-related (non-nCoV) lineages. Pangolin (red) and Bat (red) indicate the nCoV linages, Bat (black) indicates non-nCoV related lineages and Bat (orange) indicates recombinants between nCoV and non-nCoV lineages ${ }^{18}$. XJ: Xinjiang, TI: Tibet, GS: Gansu, QH: Qinghai, SC: Sichuan, YN: Yunnan, IM: Inner Mongolia, NX: Ningxia, SHX: Shaanxi, CQ: Chongqing, GZ: Guizhou, GX: Guangxi, SX: Shanxi, HN: Henan, HUB: Hubei, HUN: Hunan, GD: Guangdong, HLJ: Heilongjiang, JL: Jilin, LN: Liaoning, BJ: Beijing, TJ: Tianjin, HB: Hebei, SD: Shandong, JS: Jiangsu, AH: Anhui, SH, Shanghai, ZJ: Zhejiang, JX: Jiangxi, FJ: Fujian, HAN: Hainan. 


\section{Dramatic drop of pork supply in China since 2018}

China produces approximately $50 \%$ of the world's pigs. This corresponds to over 700 million hogs and $\sim 55$ million metric tons of pork annually, forming an industry worth over $\$ 128$ billion $^{11,19}$. Pigs had been farmed mostly in the southern provinces before 2016 . However, in recent years pig farming has radically shifted to the north, mostly as a result of the national 13th five-year development plan for environmental protection ${ }^{20}$. Hence, the ASFV outbreak started in the north and spread to the south, resulting in unprecedented damages to the Chinese pig industry (Figure 2a-f).

ASFV infections had spread to 31 provinces/regions, almost the entire country, by the fourth quarter of 2019. As of 21 November 2019, immediately before the SARS-CoV-2 outbreak in Wuhan, there were 160 reported ASFV outbreaks nationwide, among which 157 were domestic pig herds and the other three were in wild boars, according to the Ministry of Agriculture and Rural Affairs (MARA) ${ }^{21}$ (Figure 2a). Since the first case in August 2018, the Chinese governments culled pigs within a $3 \mathrm{~km}$ radius of any infected farms and adopted more stringent quarantine procedures, fast testing and reporting systems, and strict regulations on across-province transportation of live pigs and pork products (more regulation details in Supplementary Table S1) ${ }^{22}$.

Consequently, the Chinese pig industry has suffered a great loss as a result of the ASFV epidemic (Figure $2 b-c)^{22}$. A total of $\sim 1.2$ million infected pigs had been culled by the end of November 2019 (Hongkong SAR) (Figure 2d). Government data indicate a decrease between 118 and 175 million pig inventories in 2019, i.e., $27.6 \%$ to $41 \%$ year-on-year and 11.5 million metric tons reduction of pork output ${ }^{23,24}$. The scale of reduction in pork production varied greatly among provinces, which was significantly worse in large production provinces (Figure 2b-c). Interestingly, although Shandong was not the largest producer in 2019 (Figure 2b), it suffered the largest reduction in pork production (Figure 2c), followed by Henan, Sichuan, Hunan and Hubei. Surprisingly, Yunnan, as a large pig producer, experienced more ASFV outbreaks than others and had a relatively small decrease in the pork output. Nevertheless, the scale of the ASFV outbreaks and pig losses are considered to be underestimated ${ }^{25,26}$. The pig industries estimate that the number of infected pigs could be as high as $200-400$ million heads, equivalent to $\sim 40-60 \%$ of the total pig population and with a reduction of $25 \%$ in pork output ${ }^{27}$.

The Chinese government enacted a series of policy tools to tackle the pig crisis, including restoring domestic pig production with strong fiscal support, and expanding meat and seafood imports (Supplementary Note). Moreover, the life-cycle constraints of pig growth and losses in the breeding sow further contributes to the pork supply shortage. As a consequence, the southern and eastern provinces traditionally large pork consumers were experiencing a severe pork supply shortage (Figure $2 b$ ).

\section{Sharp rise in pork price and strong geographical imbalance}

The price of pork rose strikingly, more than doubling, between January and October, coincidently before the SARS-CoV-2 outbreak. Prior to 2019, the mean national hog price was below 20 Yuan/kg on average (Figure 3 ) and the price disparity among provinces was minimal (Figure 3). After ASFV infections spreading from Northern to Southern China from August 2019, the disparity in the pig prices among provinces increased sharply (Figure $2 f$ and Figure 3).

In early November 2019, roughly one month before the SARS-CoV-2 outbreak ${ }^{28}$, the average weekly wholesale pork price nationwide had risen to $52.3 \mathrm{Yuan} / \mathrm{kg}$, the highest in history, compared to $21.1 \mathrm{Yuan} / \mathrm{kg}$ in $2018^{29}$. On average, a fattened live pig weighing $120 \mathrm{~kg}$ is priced at least at 4200 Yuan in the wholesale market with pork price at 52.3 Yuan $/ \mathrm{kg}$. To put this in context, the average annual per capita disposable income for Chinese rural residents was $\sim 14,600$ Yuan in $2018^{30}$. Facing tough pork price inflation pressure, the Chinese government has been routinely releasing strong market signals that governmental pork reserves and imported pork would enter the market. In response, pork 
prices kept going down rapidly. By the end of November, which was the likely date range when the early transmission chain contracted SARS-CoV- $2^{28}$, the average price dropped to 42.3 Yuan $/ \mathrm{kg}$, i.e., $19.1 \%$ drop in just four weeks. This represents at least a 1200 Yuan loss in profit for each pig, a large margin compared to the average Chinese household income level. This led to a strong expectation that pork price would continue to drop dramatically as a result of government interventions. Stakeholders along the pig supply chain were rushed to slaughter fattened pigs and sell out the frozen inventory stockpiled during summertime.

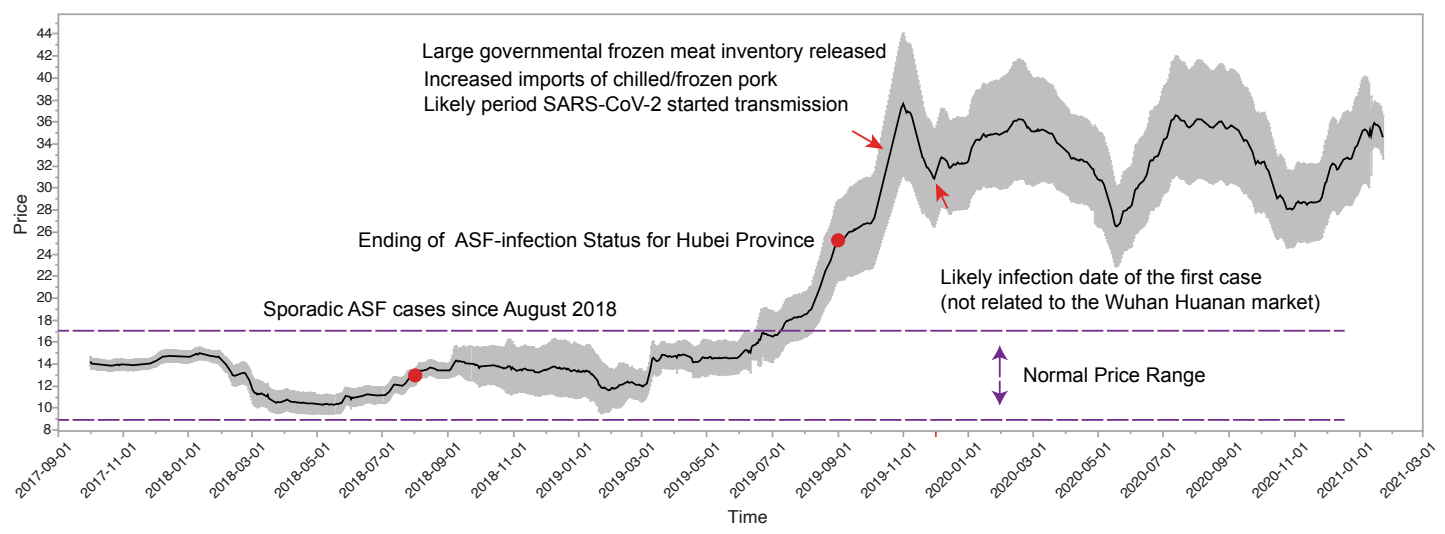

Figure 3. Dramatic increase in wholesale pig price among provinces in China, 2017-2020. Red arrow on the right of the peak indicates the likely date of the first confirmed SARS-CoV-2 case contracting the virus that is not linked to the Huanan market in Wuhan ${ }^{28}$. The black line indicates the average price and the grey bars indicate price standard deviation. By the end of November, Yunnan and Guangxi were the only two provinces still in ASFV-infection list with blockade measures for outwards pig movements while the other 29 provinces/cities were officially ASFVfree and free for hog and pork movements.

Data source: China Pig Web, https://hangqing.zhuwang.cc/shengzhu/list-63-83.html.

Geographic price disparity of pigs and pork in 2019 has led to strong incentives for crossprovince trading. Before the ASFV outbreak, the pig prices were relatively even among provinces as indicated by smaller price standard deviation (Figure 3). However, in 2019, the pig prices showed strong geographical disparity, especially in November (Figure 2f). Prices were doubled in Southern (Guangxi and Guangdong), Eastern (Fujian and Zhejiang), Central (Hunan, Jiangxi and Hubei) and Western China (Sichuan) than the rest of China (Figure 2f). Daily hog price fluctuated intensely throughout 2019 (Figure 3). Strikingly, pig price fluctuated more dramatically in southern China (Guangxi, Guangdong), extending to part of Western (Sichuan), Central (Jiangxi, Hunan and Hubei) and Eastern (Fujian) China, than in the rest of China (Figure 2f). Importantly, these provinces (e.g., Guangxi and Guangdong) with much higher pig prices and volatility traditionally consumed much more wildlife than the rest of $\mathrm{China}^{31,32}$. Moreover, these provinces overlap with the host range of the four potential hosts of the proximal SARS-CoV-2 ancestor, $R$.affinis, $R$.sinicus, $R$. ferrumequinum and $R$. malayanus ${ }^{18}$. It is striking that in Yunnan, a major pig producer in Southern China, pig prices stayed among the lowest range, 8-9 Yuan/kg cheaper than the surrounding Sichuan and Guangxi (Figure 2a-f), which were still under the government ASFV restrictions for shipping out pigs and pork products due to two ASFV outbreaks. It is conceivable that illegal movement of meat to other regions of China from Yunnan took place.

\section{Regulation on pig and pork transportation across provinces}

After confirming the first ASFV outbreak in Shenyang on $3^{\text {rd }}$ August 2018, MARA launched the Level-II emergency response and issued several policies and regulations in the hope to halt further ASFV transmission ${ }^{22,33,34}$. One of the most important measures was movement restrictions on live hogs, pork, and pork products from affected areas or regions 
(Supplementary Table S1). MARA also announced intensified requirements and inspections on pig and pork product transportation vehicles ${ }^{34}$. At first, authorities primarily suspended the movement of hogs and related pork products from the epidemic zone Shenyang City ${ }^{33}$. This measure may not have been sufficient to control ASFV transmission from Northeastern China to the rest of the country.

Regional controls/blockades have a tremendous effect for China as the country is divided between the main regions of pig production and pig consumption ${ }^{35}$. Due to rapid economic development, urbanization and governmental interventions for environmental protection and industrial development since 2016 (details in the supplement), China's pork production has gradually shifted from the developed southern and eastern regions to the less developed central, northern and western parts (Figure $2 b)^{20,35}$. However, pork consumption per capita is still much higher in the south and lower in the north ${ }^{11}$. Hence, long distance transportation of live pigs and pork products is unavoidable. There was on average 100 102 million (14 19\%) live pigs transported across provinces nationwide before the ASFV outbreak in $2018^{35}$. Long distant transportation of live animals and meat products including pigs and pork mainly relies on the freeway network. The Green Channel policy for the transportation of agricultural products along the freeways, which provides fee discounts, further facilitates long distance transportation and extends the pig supply chain across provinces ${ }^{36}$. On 10th September 2019, the central government released an announcement that piglets and chilled pork were officially permitted to enjoy the Green Channel policy for agricultural products. Breeding sows and frozen pork would have the toll-fee waived on freeway transportation between 1 September 2019 and 30 June $2020^{37}$. As of 2019, the total length of China's freeway network measured $\sim 150$ thousand kilometers (Figure $2 \mathrm{~g}$ ), the world longest by length ${ }^{24}$. Around $42 \%$ of the increase compared to 2018 were from Southern China, including Yunnan, Guizhou, Guangxi, Guangdong and Hubei (Figure 2h). Importantly, Yunnan ranked at the top with an increase of $805 \mathrm{Km}$ reaching a total length of $6003 \mathrm{Km}$ in 2019. This increase in the road network connected once remote rural areas ${ }^{12}$, and formed a transportation network with seven inter-provincial and five trans-national freeways, connecting Myanmar, Vietnam, Thailand and India ${ }^{38}$.

\section{Active consumption and supply of wildlife}

To understand whether wildlife or domesticated animals could be a potential source for alternative meat during pork shortage and price rises, we explore the cultural, legal and economic status of wildlife consumption in recent years in China. Consumption of wildlife (including farmed wildlife) is active in most regions in China. Wild animal trade and consumption takes place more frequently in Southern China, such as Guangdong, Guangxi, Fujian, Hainan and Jiangxi ${ }^{31}$. In 2004, China Wildlife Conservation Association (CWCA) reported that $46.2 \%$ urban residents had consumed wildlife and $2.7 \%$ were regular consumers $^{39}$. In January 2017, before the Chinese New Year, $52 \%$ of investigated markets were trading wildlife and $40 \%$ of investigated restaurants were providing wild animal dishes. A recent joint online survey by several nonprofit organizations in March 2020, on previous experiences of wildlife consumption, suggests that the primary consumption is for eating, followed by raising as pets, decoration, and medical uses ${ }^{32}$. Wild birds, snakes, turtles, salamanders, bamboo rats, squirrels, porcupines, deer, and wild boars are the most popular wildlife for food. Most of them were traded as live animals rather than processed products. Due to the rapid development of online shopping platforms in recent years in China, wildlife consumption has also shifted from traditional wet markets to online trading, most on Wechat, Taobao, and live broadcast platforms. These online shopping behaviors were difficult to discover, trace and monitor.

The basic principle of China's laws regarding wildlife issues is a dual track of necessary protection and rational utilization ${ }^{40}$. Wildlife Protection Law (2018) before the COVID-19 pandemic focused on the protection of endangered and precious terrestrial and aquatic wildlife, and terrestrial wildlife with important ecological, scientific and social values ${ }^{41}$. It was legal to sell, trade, purchase and eat farmed wildlife/domesticated animals and related 
products but requires legitimate proof. Various wildlife had been permitted to be farmed on a large scale by a special artificial breeding license, and to be traded in the markets by a special business license issued by the Domestic or National Forestry Administration Office before 2020 (You, 2020). In 2016, the full time and part time employment engaged with wildlife farming nationwide was around 14.09 million, generating an industry worth 520 billion RMB or 80 billion US dollars approximately (Supplementary Table S2) ${ }^{42}$. This industry contributes to the domestic economy and raises residents' income, an important part of domestic economic growth and poverty reduction. Unfortunately, there were no specified sanitary and quarantine standards and inspection systems for consumption of farmed wildlife, which has been routinely used in livestock meat production cycle, placing unprecedented risks for emerging zoonotic pathogens and animal-human transmission ${ }^{43}$.

Licensed wildlife farming was encouraged in many provinces, and financial support was provided by some local governments, especially in low-income provinces with rich natural forest and wildlife resources, such as Shandong, Guangxi, Jiangxi, Guizhou, Yunnan, Liaoning and Heilongjiang. Civets, minks, bamboo rats, deer are the most popular wildlife widely farmed in China. Minks (largest), foxes (largest) and racoon dogs (second largest) have been widely farmed in Shandong ${ }^{44}$ and Guangxi farmed a large population of bamboo rats (Rhizomys sp.). In 2019, 11.7 million pieces of mink fur-skins, 14.4 million pieces of fox fur-skins, and 13.6 million pieces of raccoon dog fur-skins were derived in China. However, there were $43.6 \%$ reduction, $17 \%$ reduction and $10.2 \%$ increase, respectively, compared to those of 2018 . Shandong ranked the top with $56.79 \%$ fur-skin production for minks and $40.2 \%$ for foxes, and second with $22 \%$ for raccoon dogs ${ }^{45}$.

Crucially, these regions also overlap with the known horseshoe bat host ranges of the proximal SARS-CoV-2 ancestor and all with well-connected freeway networks for supply/cold chains to reach Southern and Central China, such as Yunnan, Guangxi and Guangdong and Wuhan. The meat of these domesticated animals, whether they are used for fur such as mink or used for meat such as civets and bamboo rats, could conveniently act as one of the sources for alternative meat in a culture which has a particular appetite for wildlife meat.

\section{Discussion}

Major meat shortages, such as of pork between 2018-2019 in China due to the ASFV epidemic, has significant ecological/socio-economic and epidemiological consequences, which likely contributed to the use of alternative animal sources of meat and in particular increased contact with wildlife. This we hypothesis has indirectly led to the SARS-CoV-2 outbreak in Wuhan, a city in Central China $\sim 1500 \mathrm{Km}$ from Yunnan where its closest evolutionary related horseshoe bat coronavirus was sampled ${ }^{18}$. Note, the divergence of these closest bat Sarbecoviruses from the SARS-CoV-2 progenitor (corresponding to many decades of evolution) indicates the viruses that emerged in Wuhan is not necessarily from Yunnan and that sampling should be widened to other areas horseshoe bat species reside in China. It is also possible there were multiple spillover events in Wuhan as SARSCoV-2 is thought to have been circulating prior to its first association with the Huanan Seafood Market. This could be indicative of infected animals or meat being introduced into Wuhan multiple times from a single source.

The introduction and spread of ASFV in China resulted in tremendous damage to the pig industry. Containment measures in line with the OIE guidelines, such as culling and regional blockades ${ }^{46}$ exacerbated regional imbalance in the pork supply and pork prices. Under the circumstance, unusual animal and meat movements across provinces and national borders were difficult to avoid, given the significant demand for alternative meat. Banning hog movements and promoting cold chain meat supply had been proven to be an efficient means for controlling persistent ASFV transmission and easing the pork crisis. It is coincidental that another zoonotic spillover SARS-CoV-2, has emerged and is capable to humans from animal hosts such as bats, minks, raccoon dogs, bamboo rats and 
pangolins, as well as through contaminated cold chain systems ${ }^{47-51}$. The scale of the pig shortage could be extremely large ( $40-60 \%$ of the total pig population). This changed the meat consumption and human behavior, which disrupted the usual barriers of zoonotic spillovers between animals and humans. All these significantly increased probabilities of spillover and transmission from horseshoe bat species and other potential intermediate animal hosts. Moreover, China's recent development in globalization, urbanization, and transportation networks can further magnify the effect of spillovers ${ }^{52}$. Due to significantly increased animal-human contact probability for alternative meat, any animal host or contaminated meat from its place of origin can conveniently reach any mega city with an immunologically naive population to initiate a successful zoonotic transmission and subsequent pandemic ${ }^{8,53}$.

The vacuum created by the limited availability of pork stimulated irregular movements of other live animals and meat products. It may also lead to expansion of pig farming to previously unfarmed areas or even non-inhabited areas. Meanwhile, consumers substituted expensive pork with alternative cheaper meat varieties, probably breaking the barrier between wildlife and regularly consumed animals. The Chinese have a long history of using wildlife in their diet and for medicinal use. Extremely high pork price makes exotic meat substitutes more favorable, particularly in the southern provinces where people have an appetite for eating wildlife, like Jiangxi, Guangxi, Guangdong, Fujian, and Hunan. No robust evidence has been found that livestock like pigs or seafoods can be naturally infected by SARS-CoV-2 virus, but there are numerous reported cases for frozen meats/seafoods or packages contaminated with live virus leading to successful human transmission ${ }^{47}$. The Chinese government has been promoting the cold chain system to transport meat rather than transporting live pigs since mid-June 2019 due to the pork crisis. The SARS-CoV-2 virus could have been transported from southern or eastern provinces to Wuhan markets via the cold chain vehicle, either directly by infected animals or by a contaminated environment.

Cold chain successfully extends the storage time and transportation distances compared with the traditional pork supply chains. It plays a critical part for a large country like China in building a nationwide modern meat supply chain. Previous studies found that third-party cold chain logistic companies transport fresh agricultural products in a mixed way suggesting cross-contamination is possible ${ }^{54}$, as this can reduce transportation $\operatorname{cost}^{55}$. Distant transportation of live animals and meat products largely relies on freeways through the fresh agri-food green channel with fee discounts. Inspired by the favorable policies for shipping pork meat at zero freeway toll fees since the middle September 2019, extremely high pork prices, and inter-provincial price disparity, cold chain service providers likely run seafood, pork meat or any other meat business including farmed/illegal wildlife at the same time to maximize their profits. Intensive new freeway constructions nationwide in recent years, especially in Central and Southwest China, such as Hubei, Yunnan, Guizhou provide infrastructure and form the basis for meat cold chain movements (Fig 3). Road construction stretching to remote and isolated areas, in pursuit of poverty reduction and economic development, form new transport network and connect remote impoverished rural areas to modern and population-dense regions, leading to extensive human encroachment into rural areas and increased contact with new pathogens like SARS-CoV2.

Surprisingly, Shandong experienced the largest decline ( $\sim 1.7$ million metric tons) among provinces in pork production in 2019 (Fig 2c) and it is the largest producer of minks, foxes, and similar farmed wildlife in China. Moreover, Shandong is the largest seafood producing, processing, import and export province. It is known that seafood cold chains can facilitate transmission of SARS-COV- $2^{47}$. Importantly, Hubei, an inland province in Central China, is located distantly from seafood production sites and seafood suppliers must fully rely on imports from other coastal provinces. Seafood wholesale markets in Wuhan serve as the distribution centre of seafood products to the rest of the province, or even probably to its adjacent provinces given its spatial accessibility ${ }^{56}$. Guangdong, where wildlife is actively 
consumed, is an important seafoods producer serving inland provinces. Although Shandong is not generally considered in the horseshoe bat host range of the proximal SARS-CoV-2 ancestor, due to climate change, slight expansion of host range of these bat species to include Shandong is not unexpected ${ }^{57}$.

It is interesting that SARS-CoV and SARS-CoV-2 emerged at a similar time between November and early December of the year. In China, December is the starting month of the traditional peak season for meat consumption due to new year and Chinese lunar year dual holiday effects. It is the traditional period for preparing Chinese sausage and other preserved meat. In winter, wildlife is also fattened naturally and traded more as luxury meat in Chinese culture. Hence, the outbreak of two sarbecoviruses around the same time of a year may not be a coincidence ${ }^{28,58}$. Moreover, November in 2019 was unique. Pig farms and slaughterhouses rushed to sell out their fattened pigs, including frozen meat stock, due to expectation of future price drop. Although coronavirus has potential seasonality for outbreak/transmission ${ }^{59}$, the timing of this ecological/economic disturbance due to severe pork shortage is critical.

\section{Conclusion}

An animal virus infection like ASFV to a major livestock, such as pigs in China, can have drastic consequences. Our analysis shows that the ASFV epidemic and associated pork shortage likely changed the meat market structure, human/consumption behavior and wildlife/hosts contact leading to increased risk of zoonoses. The meat supply/cold chains and well-connected high-speed transportation networks may have helped to maintain transmission by transporting SARS-CoV-2 into a large immunologically naive population. Importantly, pork consumption continues to increase in China and Southeast Asia in recent years and takes up an important proportion of the daily diet. According to the recent estimation of global poverty by the economist group of WorldBank, COVID-19 pandemic generates 119-224 million new poor, out of which $60 \%$ are living in Southeast Asia, reversing a decade of poverty reduction ${ }^{60}$. As the size of impoverished population prone to food shortage increases, hunting and trading of wildlife tend to intensify either for consumption or commercial purposes. Moreover, ASF, a major livestock pandemic with $100 \%$ lethality, is currently sweeping through Southeast Asia likely causing similar meat shortages in a region where the sarbecovirus from the $\mathrm{nCoV}$ clade is also endemic in horseshoe bat species ${ }^{7}$. These conditions enable the emergence of another pandemic SARS-2.1 or SARS-3 in this region.

\section{Methods}

\section{Supply and price}

Cobweb theorem based on pig cycle theory is still widely used as the analytic tool in recent economic studies ${ }^{61-63}$. According to the pig cycle theory in economics, cyclical fluctuations are normal for agricultural commodities with long time lags from breeding decisions to output for sale ${ }^{64}$. Low price and large supply in one period will make the market saturated, followed by a smaller supply along with price rises in the next period. In return, high market price simulates larger pig supply, but drags down pig price in the succeeding period. This process repeats and forms a drifting pig cycle in the long run like a cobweb ${ }^{65}$. There are strong biological constraints for expansion in hog production when prices continually increase, but no biological constraint in response to decreasing pork prices. Hence, slaughtering and selling promptly for cash is a typical choice for most pig farmers and butcher houses.

\section{Demand for pork and alternative meats}

The economic analysis for how pork demand reacts to the price increase is based on consumer behavior theories in microeconomics. Demand is primarily driven by price and income. Price elasticities, the marginal consumption volume changes due to the price 
changes, of foods are generally much smaller than other products as daily necessities ${ }^{66}$. Pork and pork products are the traditional major sources of animal protein in China. Pork demand is observed to be robustly inelastic to price changes in most studies, with elasticity between -1.3 to 1.2 , the mean at -0.67 , most robust with smallest variance across studies out of livestock and seafoods ${ }^{61}$, as the absolute value of the price elasticity less than unity indicates price inelasticity.

Analysis of the potential changes in consumption of alternative meats as substitution due to dramatic increase of pork prices is based on the theory of consumer choices ${ }^{67,68}$. According to the theory, with a fixed expenditure budget, taking pork is a normal good in China, not luxury or inferior, if pork price increases, substitution effects and income effects will take place. Consumers will eat less pork ${ }^{69}$, alternatively cheaper meats to maintain the previous meat protein levels ${ }^{11}$. Both the relative price and absolute price differences matter to the substitution choice ${ }^{70}$. The sizes of substitution effects depend on whether alternative meats are perfect substitutes or imperfect substitutes for pork. A wider range of varieties leads to greater substitution possibilities ${ }^{61}$. Chicken is frequently found a closer substitute for pork in the Chinese diet ${ }^{71}$. Wildlife/domesticated animals appear to be imperfect substitutes but provide a wider range of varieties. The likelihood of substitution may vary depending on various factors, such as income level, relative prices, diet culture, geographic locations, variety availability, and consumer preference, etc. Since August 2019, pork prices had risen far from its normal price range, the probability of consuming wildlife and their products increased in the areas with diet culture and market access to wildlife varieties.

\section{Government frozen pork reserve effects}

Government storage is supposed to help the supply and expectations and thus reduce dramatic price fluctuations ${ }^{72}$. The competitive storage model is frequently used for analyse ${ }^{63,72}$. To analyze the market effects of government emergency pork reserves, this study adopts the analytic paradigm of augmented Competitive Storage model proposed by Tan\&Zeng (2018). Following their theory, marginal costs of pork reserve is considered at zero since costs were not an important consideration factor during the stockpiling period ${ }^{63}$. Moreover, asymmetric information effects of price transmission should be taken into consideration. When supply exceeds demand and prices (expect to) go down, hogs are slaughtered and stored frozen for future release. Afterwards, when prices went up, these frozen meats were released and transported. Hence, there was strong market expectation prior to important Chinese holidays or in the face of incredibly high market prices, which coincides exactly with the date of the first COVID-19 case contracted SARS-CoV-2 reported in Wuhan (Figure 3).

\section{Data}

\section{Pig production and import}

Annual provincial pig, pork production and pig inventory data are derived from China Rural Statistical Yearbook (2020) and (2019) ${ }^{24,30}$.

Annual meat import data including pork, beef, mutton, poultry, and seafood were obtained from the trade database of the United Nation: https://comtrade.un.org/data/.

\section{Pig prices}

Average weekly prices for pork meat nationwide from 2010 to 2019 were obtained from the Ministry of Commerce. To analyse the price distribution, fluctuation and dynamics, daily hog prices were obtained from China Pig Web by a custom Python script: https://hangqing.zhuwang.cc. Hog prices rather than pig prices were used due to the concerns as follows. First, there is no open official data for daily pork prices for all provinces. MOC releases historical daily data for some provinces, but do not include Hubei province. Second, China Pig Web is a relatively credible and authoritative data provider which is a listed company on Shanghai Stock Exchange Centre. It provides continual daily provincial pig price data. The liaison of the website stated that the data are derived comprehensively from diverse sources, including regional investigating staff, slaughterhouse, hog wholesale 
market, and official statistics. Third, the pork price is also available on the China Pig Web, but they are imbalanced and unstable. Fourth, studies on China's pig supply chain indicate that there is no time lag to transmit the pig prices to the pork prices. Finally, there are bilateral transmission between pork price and pig price. It is found that fluctuation in pork price immediately passed to pig prices ${ }^{16,73}$.

\section{ASF outbreaks}

The records of African Swine Fever outbreaks in China and in Southeast Asia countries were obtained from OIE:

https://www.oie.int/wahis 2/public/wahid.php/Diseaseinformation/Wl.

\section{Freeway status}

The freeway construction data was obtained from Statistical Yearbooks (2020) from 31 provinces.

\section{Acknowledgements}

DLR and JH are funded by the Medical Research Council (MC_UU_12014/12).

\section{Competing interests}

The authors declare no competing interests. 


\section{Reference}

1 Andersen, K. G., Rambaut, A., Lipkin, W. I., Holmes, E. C. \& Garry, R. F. The proximal origin of SARS-CoV-2. Nature Medicine 26, 450-452, doi:10.1038/s41591-020-0820-9 (2020).

2 Boni, M. F. et al. Evolutionary origins of the SARS-CoV-2 sarbecovirus lineage responsible for the COVID-19 pandemic. Nature Microbiology 5, 1408-1417, doi:10.1038/s41564-020-0771-4 (2020).

3 Latinne, A. et al. Origin and cross-species transmission of bat coronaviruses in China. Nature Communications 11, doi:10.1038/s41467-020-17687-3 (2020).

4 Zhang, Y.-Z. \& Holmes, E. C. A Genomic Perspective on the Origin and Emergence of SARS-CoV-2. Cell 181, 223-227, doi:10.1016/j.cell.2020.03.035 (2020).

Zhou, H. et al. A Novel Bat Coronavirus Closely Related to SARS-CoV-2 Contains Natural Insertions at the S1/S2 Cleavage Site of the Spike Protein. Current Biology 30, 2196-2203.e2193, doi:10.1016/j.cub.2020.05.023 (2020).

$6 \quad$ Zhou, P. et al. A pneumonia outbreak associated with a new coronavirus of probable bat origin. Nature 579, 270-273, doi:10.1038/s41586-020-2012-7 (2020).

Wacharapluesadee, S. et al. Evidence for SARS-CoV-2 related coronaviruses circulating in bats and pangolins in Southeast Asia. Nature Communications 12, doi:10.1038/s41467-021-21240-1 (2021).

Parrish, C. R. et al. Cross-Species Virus Transmission and the Emergence of New Epidemic Diseases. Microbiology and Molecular Biology Reviews 72, 457-470, doi:10.1128/mmbr.00004-08 (2008).

9 Plowright, R. K. et al. Pathways to zoonotic spillover. Nature Reviews Microbiology 15, 502-510, doi:10.1038/nrmicro.2017.45 (2017).

$10 \mathrm{Wu}, \mathrm{T}$. et al. Economic growth, urbanization, globalization, and the risks of emerging infectious diseases in China: A review. Ambio 46, 18-29, doi:10.1007/s13280-0160809-2 (2016).

Mason-D'Croz, D. et al. Modelling the global economic consequences of a major African swine fever outbreak in China. Nature Food 1, 221-228, doi:10.1038/s43016020-0057-2 (2020).

Department of Transport of Yunnan Province. Work Plan for 2019 by Department of Transport of Yunnan Province, <http://www.ynjtt.com/ltem/249250.aspx> (2019).

Vergne, T. et al. Pig empire under infectious threat: risk of African swine fever introduction into the People's Republic of China. Veterinary Record 181, 117-117, doi:10.1136/vr.103950 (2017).

Blome, S., Franzke, K. \& Beer, M. African swine fever - A review of current knowledge. Virus Research 287, doi:10.1016/j.virusres.2020.198099 (2020). (Kenya Colony). Journal of Comparative Pathology and Therapeutics 34, 159-191, doi:10.1016/s0368-1742(21)80031-4 (1921). Chinese pork and pig market. British Food Journal 120, 120-132, doi:https://doi.org/10.1108/BFJ-02-2017-0056 (2018).

Zhou, G., Zhang, W. \& Xu, X. China's meat industry revolution: Challenges and opportunities for the future. Meat Science 92, 188-196 (2012).

18 Lytras, S., Hughes, J., Xia, W., Jiang, X. \& Robertson, D. L. Exploring the natural origins of SARS-CoV-2. bioRxiv, doi:10.1101/2021.01.22.427830 (2021).

Woonwong, Y., Do Tien, D. \& Thanawongnuwech, R. The future of the pig industry after the introduction of African swine fever into Asia. Animal Frontiers 10, 30-37 (2020). doi:https://doi.org/10.1038/s41893-019-0391-2 (2020).

MARA. Press Release on the Pig

$<$ http://www.moa.gov.cn/hd/zbft news/szscxs/> (2019a).

22 Wang, T., Sun, Y. \& Qiu, H.-J. African swine fever: an unprecedented disaster and challenge to China. Infectious diseases of poverty $7,1-5$, doi:https://doi.org/10.1186/s40249-018-0495-3 (2018).

MARA. Pig Inventory Information from Survilliance on 400 counties by October 2019, $<$ http://www.gov.cn/xinwen/2019-11/29/content 5457147.htm> (2019b). 
Statistics Press, 2020).

Costard, S., Zagmutt, F. J., Porphyre, T. \& Pfeiffer, D. U. Small-scale pig farmers' behavior, silent release of African swine fever virus and consequences for disease spread. Scientific Reports 5, doi:10.1038/srep17074 (2015). Inouye, A. Livestock and Products Semi-annual of Peoples Republic of China. (United States Department of Agriculture, Beijing, 2020).

27 Rabobank. Global Animal Protein Outlook 2020. (2019).

$28 \mathrm{Li}, \mathrm{Q}$. et al. Early Transmission Dynamics in Wuhan, China, of Novel CoronavirusInfected Pneumonia. New England Journal of Medicine 382, 1199-1207, doi:10.1056/NEJMoa2001316 (2020).

29 Ministry of Commerce. in Weekly (CIF Ministry of Commerce, Beijing, 2021).

30 National Bureau of Statistics of China. China Rural Statistical Yearbook 2019. (China Statistics Press, 2019).

31 Meng, M., Lu, L., Yin, F. \& Xu, L. Status of Wildlife Trade as Food in South China. Chinese Journal of Wildlife 30, 158-160 (2009).

China Development Brief. 5211 observations can tell you where wild animal consumption used to take place. (2020).

33 MARA. Ministry of Agriculture and Rural Affairs launched Level-II Emergency Response <http://www.moa.gov.cn/ztzl/fzzwfk/gzdt/201808/t20180803 6155300.htm> (2018).

34 Food and Agriculture Organization. LATEST ASF China situation update, $<$ http://www.fao.org/ag/againfo/programmes/en/empres/ASF/2018/Situation update $2018 \quad 11$ 16.html $>$ (2018).

Sun, S., Li, W. \& He, Z. Analysis on changing and influencing factors of pork market competitiveness in China from the perspective of inter-provincial supply. Journal of Henan Agricultural University 54, 879-887 (2020).

36 Bai, Z. et al. China's livestock transition: Driving forces, impacts, and consequences. Science Advances 4, eaar8534 (2018).

37 China State Council. (ed China State Council) (Beijing, 2019).

38 Yunnan Government. Yunnan Investment Guide (2019), $<$ http://invest.yn.gov.cn/ZWArticlelnfo.aspx?id=17919> (2019).

39 Wu, X.-p. \& Hu, M. On wild animals protection by criminal laws in China. Journal of Central South Forestry University 24, 8-12 (2004).

40 You, M. Changes of China's regulatory regime on commercial artificial breeding of terrestrial wildlife in time of COVID-19 outbreak and impacts on the future. Biological Conservation 250, 1-8 (2020).

41 NPC Standing Committee. (ed Standing Committee of the National People's Congress (NPC)) (Beijing, 2018).

42 Chinese Academy of Engineering. Report on Sustainable Development Strategy of China's Wildlife Farming Industry (in Chinese). (Beijing, 2017).

43 Xue, K. Dual market failures and Correction Measures of regulation on wildlife industry: an legal analysis of the illegal wildlife supply chain Law and Economy 4, 99-107 (2020). Jiangxi Newspaper. Valuable Experiences from Civet farming in Wan'an County for Getting Rid of Poverty, $<$ http://www.forestry.gov.cn/main/72/20191128/172200782346423.html> (2019).

Liu, H., Li, J., Li, H. \& Gong, L. Mink, Foxe, and racoon dog Farming in China and Suggestions. Special Economic Animal and Plant 23, 10-12 (2020).

Ding, Y. \& Wang, Y. Big government: The fight against the African Swine Fever in China. Journal of Biosafety Biosecurity 2, 44-49 (2020).

47 Zhang, Y. et al. Genomic characterization of SARS-CoV-2 identified in a reemerging COVID-19 outbreak in Beijing's Xinfadi market in 2020. Biosafety and Health 2, 202205, doi:10.1016/j.bsheal.2020.08.006 (2020).

48 Oude Munnink, B. B. et al. Transmission of SARS-CoV-2 on mink farms between humans and mink and back to humans. Science 371, 172-177, doi:10.1126/science.abe5901 (2021).

49 Freuling, C. M. et al. Susceptibility of Raccoon Dogs for Experimental SARS-CoV-2 Infection. Emerging Infectious Diseases 26, 2982-2985, doi:10.3201/eid2612.203733 (2020).

50 Dong, B. Q. et al. Detection of a Novel and Highly Divergent Coronavirus from Asian Leopard Cats and Chinese Ferret Badgers in Southern China. Journal of Virology 81, 
Jin, D.-Y. et al. Coronavirus testing indicates transmission risk increases along wildlife supply chains for human consumption in Viet Nam, 2013-2014. Plos One 15, doi:10.1371/journal.pone.0237129 (2020).

$52 \mathrm{Wu}, \mathrm{T}$. The socioeconomic and environmental drivers of the COVID-19 pandemic: A review. Ambio Jan, 1-12, doi:10.1007/s13280-020-01497-4 (2021).

53 Ruan, Y., Wen, H., He, X. \& Wu, C.-I. A theoretical exploration of the origin and early evolution of a pandemic. Science Bulletin, doi:10.1016/j.scib.2020.12.020 (2020).

Zhao, H., Liu, S., Tian, C., Yan, G. \& Wang, D. An overview of current status of cold chain in China. International Journal of Refrigeration 88, 483-495, doi:10.1016/j.jirefrig.2018.02.024 (2018).

Huang, Y. New ideas about the development of fresh agro-product cold chain logistics in the E-commerce retail mode. Industrial Innovation 14, 15-16, doi:10.16457/j.cnki.hbhjjlw.2020.03.016 (2020).

56 Yang, J., Guo, A., Li, X. \& Huang, T. Study of the impact of a high-speed railway opening on China's accessibility pattern and spatial equality. Sustainability 10, 2943 (2018).

57 Beyer, R. M., Manica, A. \& Mora, C. Shifts in global bat diversity suggest a possible role of climate change in the emergence of SARS-CoV-1 and SARS-CoV-2. Sci Total Environ, 145413, doi:c (2021).

58 Feng, D. et al. The SARS epidemic in mainland China: bringing together all epidemiological data. Tropical Medicine \& International Health 14, 4-13, doi:10.1111/j.1365-3156.2008.02145.x (2009).

59 Merow, C. \& Urban, M. C. Seasonality and uncertainty in global COVID-19 growth rates. Proceedings of the National Academy of Sciences 117, 27456-27464, doi:10.1073/pnas.2008590117 (2020).

60 Lakner, C., Yonzan, N., Mahler, D. G., Aguilar, R. A. C. \& Wu, H. in WorldBank Blogs Vol. 2021 (Worldbank, 2021).

61 Chen, D., Abler, D., Zhou, D., Yu, X. \& Thompson, W. A meta-analysis of food demand elasticities for China. Applied Economic Perspectives and Policy 38, 50-72 (2016).

He, P., Quan, L. \& Ma, J. An Emprical Study on the 'Pork Price Cycle' of Chinese CPI. Inquiry Into Economic Issues 8, 17-22 (2013).

63 Tan, Y. \& Zeng, H. Price transmission, reserve regulation and price volatility. China Agricultural Economic Review 11 (2019).

64 Ezekiel, M. The Cobweb Theorem. Quarterly Journal of Economics 52, 255-280 (1938).

65 Harlow, A. A. The Hog Cycle and Cobweb Theorem. Journal of Farm Economics 42, 842-853 (1960).

66 Andreyeva, T., Long, M. W. \& Brownell, K. D. The impact of food prices on consumption: a systematic review of research on the price elasticity of demand for food. American journal of public health 100, 216-222 (2010).

67 Elzerman, J. E., Hoek, A. C., Van Boekel, M. A. \& Luning, P. A. Consumer acceptance and appropriateness of meat substitutes in a meal context. Food Quality Preference 22, 233-240 (2011).

Lattin, J. M. \& McAlister, L. Using a variety-seeking model to identify substitute and complementary relationships among competing products. Journal of Marketing Research 22, 330-339 (1985).

69 Green, R. et al. The effect of rising food prices on food consumption: systematic review with meta-regression. BMJ 346, f3703, doi:10.1136/bmj.f3703 \%J BMJ : British Medical Journal (2013).

70 Azar, O. H. Do people think about absolute or relative price differences when choosing between substitute goods? Journal of Economic Psychology 32, 450-457 (2011).

71 Liu, Z. An Analysis for the Price Correlations of Major Livestock Meats in China: Estimating Dynamic Relationships between Pork Prices and Poultry Prices. Price: Theory\&Practice 357, 81-83 (2014).

72 Serra, T. \& Gil, J. M. Price volatility in food markets: can stock building mitigate price fluctuations? European Review of Agricultural Economics 40, 507-528 (2013).

$73 \mathrm{XU}$, S.-w. et al. Price Transmission in China's Swine Industry with an Application of MCM. Journal of Integrative Agriculture 11, 2097-2106, doi:https://doi.org/10.1016/S2095-3119(12)60468-7 (2012). 